\title{
Recent progress in the development of the Journal of Business Economics
}

\section{Günter Fandel ${ }^{1}$}

Published online: 3 October 2020

(C) The Author(s) 2020

\section{- Additional Editor-in-Chief}

I am pleased to announce that the Journal of Business Economics has moved to having now two Editors-in-Chief: Wolfgang Breuer has been additional Editor-in-Chief of the Journal of Business Economics since July 2020. I warmly welcome him in this new role and look forward to successfully cooperate with him.

- Springer nature became a signatory of DORA

By signing up DORA (Declaration on Research Assessment) in May 2020, also including now the Journal of Business Economics, Springer Nature likes to demonstrate its clear commitment to researchers in enabling choice and supporting a balanced and fair way of addressing impact and quality and continues to engage with the open and informed debate on the future of scholarly research assessment.

Beeing a DORA-compliant offers a wide array of article-level metrics (accesses, citations, altmetrics, impact factor, submission to first decision, downloads, and submission to acceptance) that can be used to assess the quality of published research. Funding institutions may ask the universities and other research institutions which employ the researchers they fund to embrace the principles of DORA.

- Editorial status report

In 2019 there were 278 manuscripts under review; 189 of them were finally decided.

During the peer review process, submitted manuscripts go through one more revision stages leading up to acceptance or rejection. Figure 1 summarizes the activity for the journal office between January 1st and December 31st of each year. The rejection rate for a year is calculated as the number of rejected manuscripts in this year compared to the total number of decisions in this year, which is defined here as the number of rejected manuscripts plus the number of accepted manuscripts.

\section{Günter Fandel}

guenter.fandel@fernuni-hagen.de

1 Center for Production Economics and Decision Support, FernUniversität in Hagen,

Universitätsstr. 41, 58084 Hagen, Germany 

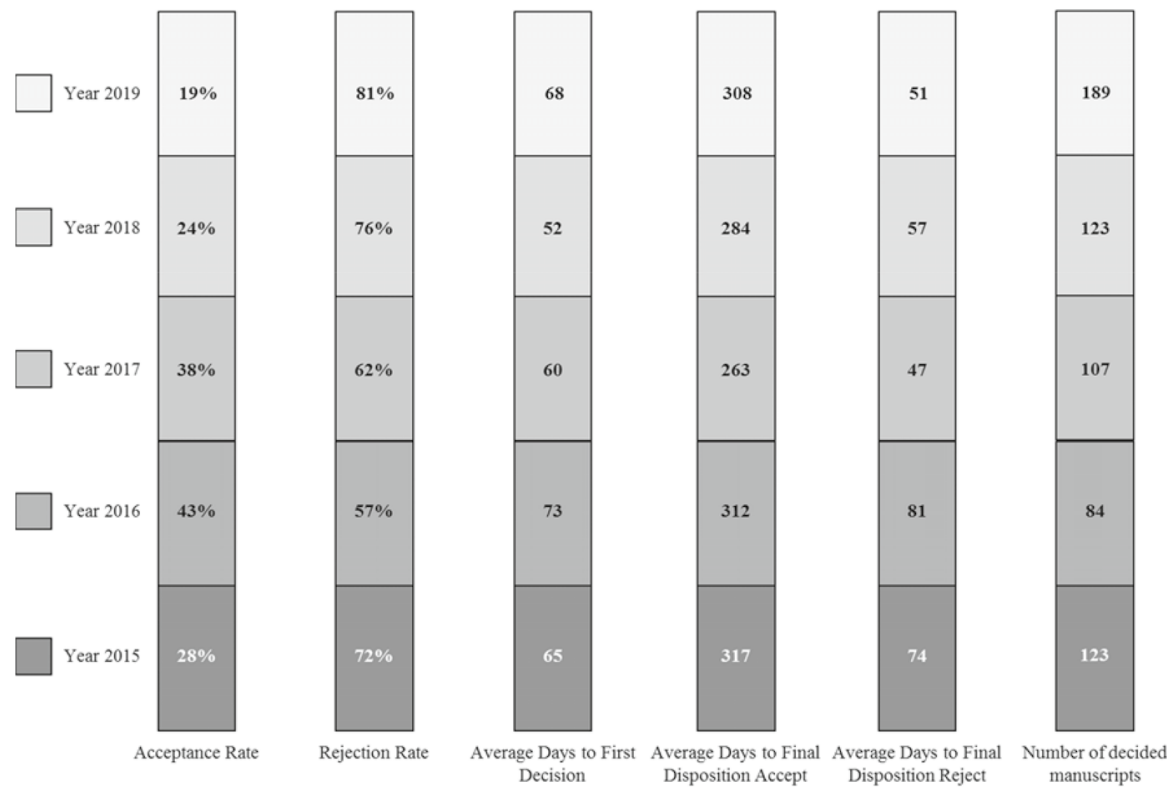

Fig. 1 Editorial status summary 2015-2019

- Downloads in 2013-2019

Downloads of full-text articles are a very good indicator of the interest of the scientific community on the paper of the journal and their content. This concerns in a positive way to two aspects simultaneously: the relevance of the topic as well as the quality of the articles. As can be seen by Fig. 2, we had already about 60,000 downloads in 2013, in the first year after "Zeitschrift für Betriebswirtschaft" was transformed into the "Journal of Business Economics". In 2019, the downloads have increased over 161,000.

In addition, Table 1 gives an information about which articles, published in the year 2014-2019, have been downloaded most frequently in the year 2019.

\section{Best paper award 2019}

By decision of the editors of the Journal of Business Economics the Best Paper Award 2019 is given to Julia Müller and Christiane Schwieren for their contribution "Big Five Personality Factors in the Trust Game", printed version in issue 1/2020. By this the editors like to prize a qualitatively outstanding publication. The editors and the publisher cordially congratulate the authors on this award.

The authors write in the abstract of their paper: "Growing interest in using personality variables in business and economic research has led to the question of whether personality, as measured by psychology, is useful to predict economic 


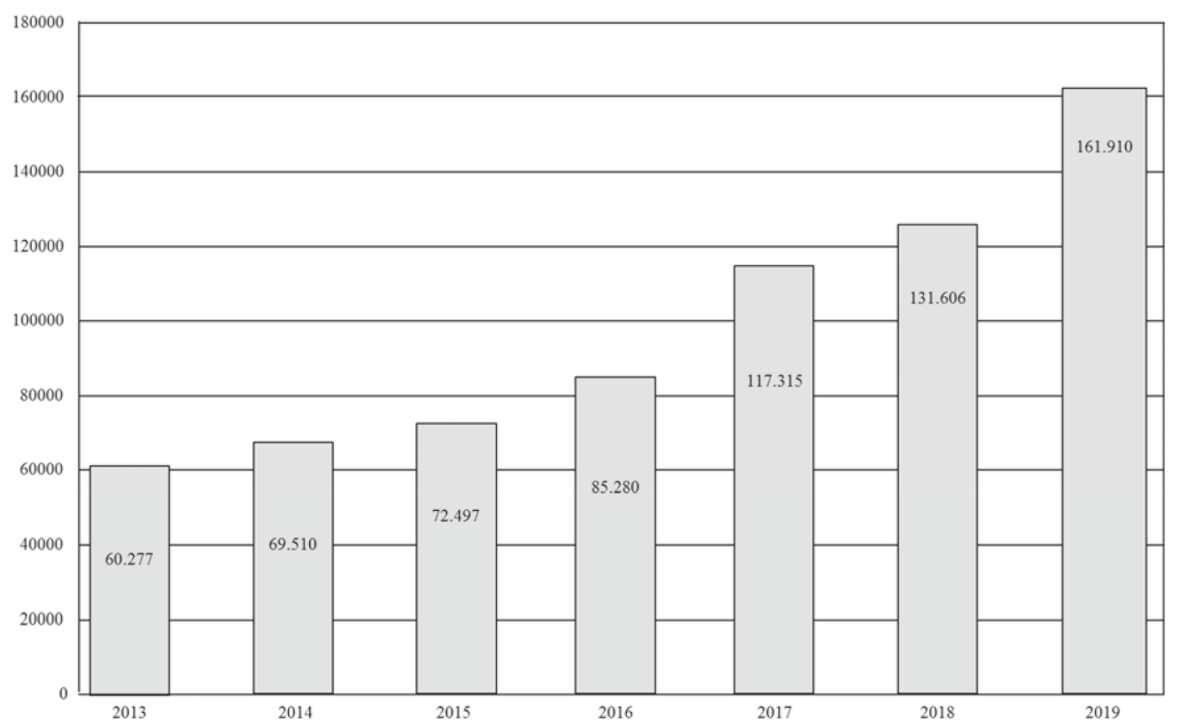

Fig. 2 Successful full-text article downloads in 2013-2019

behavior. While personality can undoubtedly influence large-scale economic outcomes, it is less clear if personality variables can also be used to understand microbehavior in games. We experimentally test the impact of personality factors (measured using the big five model) on behavior in the Trust Game. Overall, we find that personality can contribute to explaining the behavior of the first player, the trustor, whereas, the behavior of the second player, the trustee, cannot be explained by their personality. In fact, the trustee's behavior is instead affected by the first player's behavior, i.e., the second player's response depends on whether or not the first player has trusted the second player."

Julia Müller has been holding the Chair of Management at the University of Osnabrück, School of Business Administration and Economics, since June 2019. She studied mathematical economics at the University of Bielefeld. In July 2012 she received her $\mathrm{PhD}$ from the University of Heidelberg doing research in the field of behavioral and experimental economics. Afterwards Julia Müller joined the Behavioral Economics group of Prof. Dr. Peter P. Wakker and worked for three years as an assistant professor at the Erasmus University Rotterdam. In April 2019 she received her Habilitation from the University of Münster (venia legendi for Business Adminstation).

Christiane Schwieren is full professor of Organizational Behavior at Ruprecht Karls University of Heidelberg. Before coming to Heidelberg in 2009, she held positions as assistant professor of economics at Universitat Pompeu Fabra, Barcelona (Spain) and as Post-Doctoral Fellow at the University of Mannheim (SFB 504). In 2006 she was a 3-months visitor at Kyoto Sangyo University in Japan. Christiane Schwieren studied psychology (Diploma in 1999), Political Science and History (MA in 1997) at the University of Heidelberg. She did her PhD in economics 


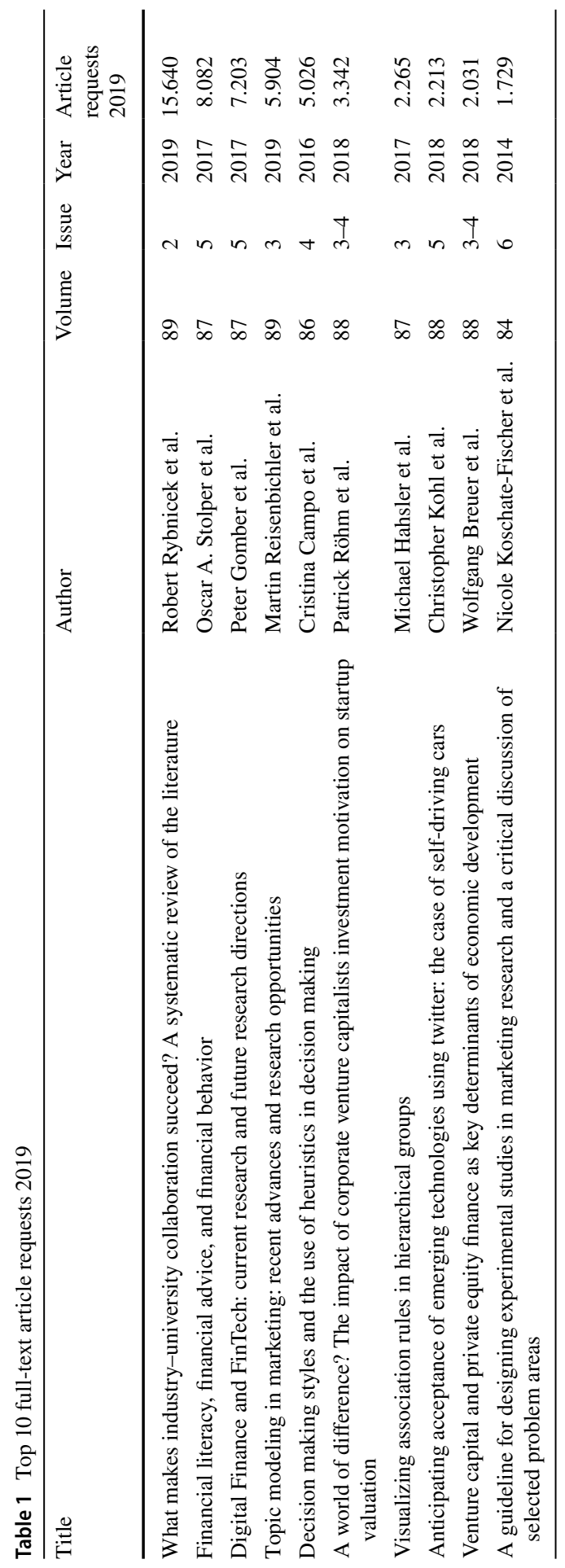


at Maastricht University in 2003. Her research is interdisciplinary, focusing on the effects of personal characteristics of actors on individual and group behavior, mainly with respect to age, gender and personality. Furthermore, she is interested in how stress and mental disorders affect economic decision making. Methodologically, she uses experimental methods and collaborates with neuroscientists, psychologists and other social scientists. She publishes in top psychological and economic field journals.

\section{Best reviewer award 2019}

Connected with giving away the Best Reviewer Award the editors and the publisher would like to thank all reviewers for their support to provide for best quality publications in the Journal of Business Economics. As representative for all reviewers of the last year Paul Wentges from the Ulm University is given the Best Reviewer Award 2019. The editors and the publisher cordially congratulate him on this honour.

Paul Wentges (born 1964 in Rees, NRW) earned his Diploma in Mathematics and Management at Ulm University and his Master of Science in Mathematics at Syracuse University before receiving his doctoral degree (Dr. oec.) at the University of St. Gallen (HSG). He subsequently worked at the Westdeutsche Landesbank in Düsseldorf, before he returned to Ulm University for his habilitation (Venia Legendi) in Business Administration. From 2003 to 2008, Paul Wentges was professor at the Institute for Strategy and Managerial Accounting at the Vienna University of Economics and Business (WU). Since 2008, he is director of the Institute for Management Accounting and Control at Ulm University, where he also served as dean of the Faculty of Mathematics and Economics. His research interests include Management Control Systems, Performance Management, Family Businesses, Corporate Governance and Stakeholder Management.

\section{Funding Open Access funding enabled and organized by Projekt DEAL.}

Open Access This article is licensed under a Creative Commons Attribution 4.0 International License, which permits use, sharing, adaptation, distribution and reproduction in any medium or format, as long as you give appropriate credit to the original author(s) and the source, provide a link to the Creative Commons licence, and indicate if changes were made. The images or other third party material in this article are included in the article's Creative Commons licence, unless indicated otherwise in a credit line to the material. If material is not included in the article's Creative Commons licence and your intended use is not permitted by statutory regulation or exceeds the permitted use, you will need to obtain permission directly from the copyright holder. To view a copy of this licence, visit http://creativecommons.org/licen ses/by/4.0/.

Publisher's Note Springer Nature remains neutral with regard to jurisdictional claims in published maps and institutional affiliations. 